\title{
Multi-Criteria Spatial Analysis of Building Layouts
}

\author{
Hissam Tawfik and Atulya Nagar, \\ Intelligent and Distributed Systems \\ Research Laboratory, \\ Liverpool Hope University, \\ Liverpool, UK
}

\author{
Terrence Fernando, \\ Future Workspaces Research \\ Centre, University of Salford, \\ Manchester, UK
}

t.fernando@salford.ac.uk

\section{tawfikh@hope.ac.uk nagara@hope.ac.uk}

\begin{abstract}
This paper proposes a multi-criteria based approach for the analysis of building layouts, from space quality and cost related perspectives. A computational prototype is developed to analyse a building layout from various accessibility related measures in order to evaluate the quality of the building special layout. A case study is used to demonstrate the assessment of a building layout based on a range of criteria.
\end{abstract}

Keywords: Space analysis, building layouts, multi-criteria.

\section{Introduction}

Designing building layouts to maximise the space use and improve accessibility inside buildings are important consideration for building designers and architects, and forms an important stage of conceptual building design and client briefing. Computer-aided support tools for building designs could benefit designers in gaining advanced capabilities for the manipulation, organization and representation of design data. Such capabilities would be highly beneficial to the design process, particularly when different design specialists work together to provide the best possible design solution based on a number of criteria and evaluation perspectives.

However, little research has been carried out to develop computer-aided and IT tools to support the production of spatial building layouts. Spatial analysis of a building, which involves organizing the building space layout in order to facilitate people's activities, is among the most challenging tasks of the building design and planning process. Efficient simulation tools are therefore needed to analyze a variety of building spaces for different space quality criteria, and ultimately generate improved layout plans.

This paper proposes to investigate the space analysis of building layout designs and its effects on the local and global accessibility of the layout. At this stage accessibility is evaluated using two

Material published as part of this publication, either on-line or in print, is copyrighted by the Informing Science Institute. Permission to make digital or paper copy of part or all of these works for personal or classroom use is granted without fee provided that the copies are not made or distributed for profit or commercial advantage AND that copies 1) bear this notice in full and 2) give the full citation on the first page. It is permissible to abstract these works so long as credit is given. To copy in all other cases or to republish or to post on a server or to redistribute to lists requires specific permission and payment of a fee. Contact Publisher@InformingScience.org to request redistribution permission. approaches; a standard accessibility from a single perspective based purely on the connections between the spaces that adopts the space syntax concept (Hiller et al, 1983), and a multi-criteria accessibility assessment that combines measures of travel cost, comfort and quality. 


\section{Related Work}

Spatial orientation is understood as people's ability to identify their location in order to navigate in a given environment, both cognitively and behaviourally (Prestosky \& Roskos-Ewolsen, 2000; Rovine \& Weisman, 1989; Passini, 1984). There are a number of design features that may influence the way people find their way inside a building, and different factors that facilitate space orientation within a building. According to Gifford (1997), these include the visibility of the destination and the general layout of the environment. Weisman (1981) urged that space configuration has an important influence on way finding. O'Neill (1991) and Garling et al. (1983) found that the complexity of a setting, such as the quantity of possible paths between a number of nodes in a system, has an influence on way finding abilities.

Most of the recent technological advances in the field of space analysis are related to space syntax (Hiller et al, 1983) proposes a number of methods to analyse relationships between social patterns and spatial organization.

Space syntax focuses on the topology of a spatial setting and the patterns created by the relationships between the spaces, but not on its size or its shape. The main finding of space syntax research here is that global organization acts as a mechanism that generates people's patterns of movement within spaces. Studies had shown that spatial organization apart from its location, facilities and density has an important effect on the way people move through spaces, thus, on the way people could meet other people by chance, for example. Hence spatial configuration promotes people's encounters as well as makes it possible for them to avoid each other, shaping social patterns (Hillier et al, 1983; Hillier \& Hanson, 1984).

Space syntax also provides tools to analyze and describe the spatial configurations and explore whether the measures that space syntax provides could be related with way finding. One way to measure spatial relations is through the integration or accessibility measure. Peponis et al. (1990) used the space syntax methodology to study the relationship between the integration values of all the spaces of a hospital and way finding tasks. They found that people tend to travel through more integrated spaces when they know the setting, as well as when they are looking for a destination, or if they get lost Ortega, et al. (2001).

Haq (1999a), focused on the influence of expectation for exploration in way finding and found that people tend to go toward places where they could have better visual access to other spaces.

\section{Spatial Layout Modeling}

Our prototype for the analysis of building layout is designed to evaluate the accessibility measures of a space given the accessibility and cost related measures for safety, comfort, space quality, and traveling distance. The accessibility evaluation method adopts the space syntax concept and requires the links (e.g. doors) between spaces (e.g. rooms) to be determined, and the layout to be represented as a connection graph. The connections are then evaluated using the number of links required to traverse from one space to another, and the overall complexity by which the various spaces connect together to form a global spatial configuration. The analysis is performed from single criterion perspective using space syntax concepts and from multi-criteria perspectives in order to analyze the layout for different situations.

Our prototype translates a given layout for spatial analysis into spaces and links in order to determine the accessibility measures of the spaces given the criteria of cost and relationship between spaces. The prototype consists of input, analysis, and output sections.

The input section defines the spaces and links for the building layout, as well as the travel cost, comfort and quality related values for the building spaces. The analysis sections utilises the Dijkstra minimum path finding algorithm to obtain optimum and minimum-cost paths between 
spaces in the building. Dijkstra optimization algorithm (Dijkstra, 1959) is mainly used for determining the shortest paths in graphs. It modifies the breadth-first strategy by always expanding the lowest cost leaf node first as measured by a function $g(n)$ that gives the path cost from the start node to node n. Dijkstra is an optimal algorithm and its time complexity is the same as for breathfirst search (Russell and Norvig, 1995). The output section displays a graphical and numerical representation of the local and global accessibility of the spatial layout.

\section{Scenario Example}

The prototype was used to analyze the layout of the main building at Liverpool Hope University campus, as a proof of concept scenario. The analysis is performed in order to determine the accessibility of various rooms inside the building from a number of perspectives.

The layout of the building is shown in Figure 1. The numbers associated with the spaces represent the different room numbers of the main building. The spaces "109", "110", "209", " $210 "$, " $309 "$, "310", "409", "410" are links between different floors of the building i.e. "109" on the first floor is linked to "209" on the second floor which in turn is linked to " 309 " on the third floor. These links determine the route to get from a space located on one floor to another space located on another floor.

In order to analyze the layout from single and multi-criteria perspectives, the following analysis is performed on the layout.

1. Minimum cost path finding between any start and destination spaces (rooms) using the Dijkstra algorithms

2. The local accessibility value of a particular room by determining the mean value of the set of the minimum cost paths from this room to every other room in the layout

3. The global accessibility value of the whole layout by determining the mean value of the set of the local accessibility values of all the rooms in the layout

The local accessibility values are graphically represented using gray level scale such that the darker a gray room is, the more accessible it is to a particular room based on the minimum-cost path measure. Similarly global accessibility is graphically represented that such darker-gray coloured spaces represent the most locally accessible rooms in the building layout.

\section{Single Criterion Analysis}

The single criterion considers that the minimal cost path between two rooms is the path with the lowest number of links between the rooms.

Consider the path between spaces " 401 " and " 208 " for minimum number of links. The minimal cost path to get from " 401 " to " 208 " using the Dijkstra algorithm is shown in Figure 1a. The local accessibility of the space " 401 " is shown in Figure $1 \mathrm{~b}$ and the global accessibility of the building is shown in Figure 1c.

\section{Multi-Criteria Analysis}

The multi-criteria analysis determines the minimum-cost path between spaces based on the cost measures of travel overhead, comfort and quality of the spaces. These criteria are arrived at heuristically by taking into account the travel cost with reference to cost related to travelling distance, time and effort. The comfort criterion is used to account for important aspects such noise and size, while quality accounts for factors such as safety and aesthetic value of the space. 


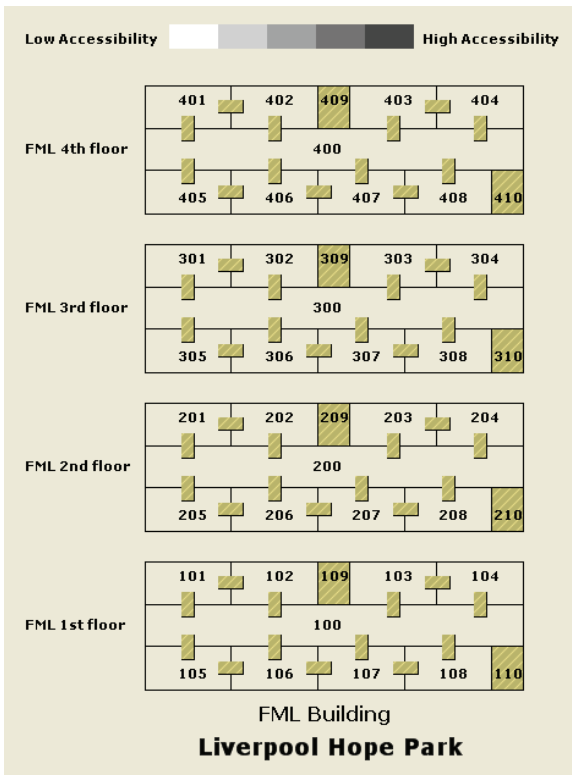

Figure 1: Building Layout Example

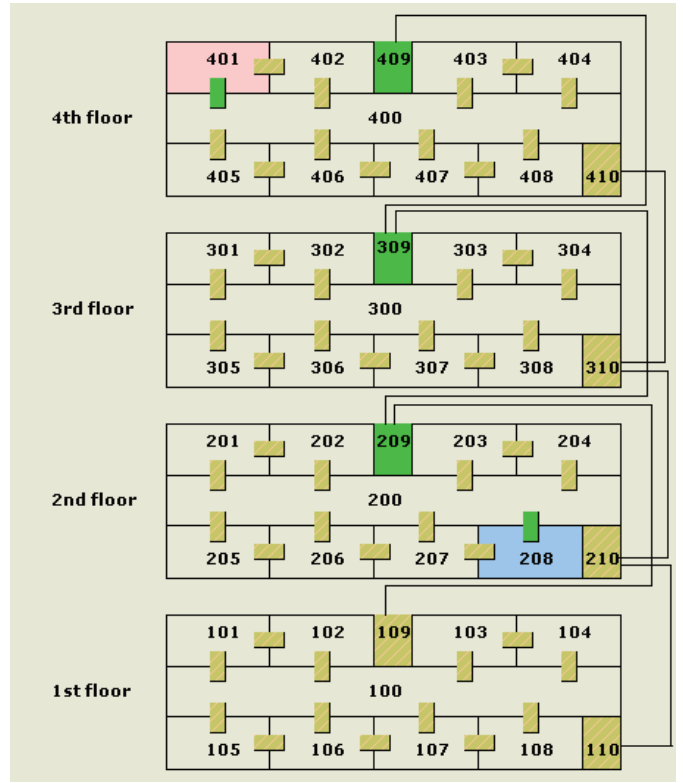

Figure 1a: Optimized Path for Single Criterion from 401 to 208

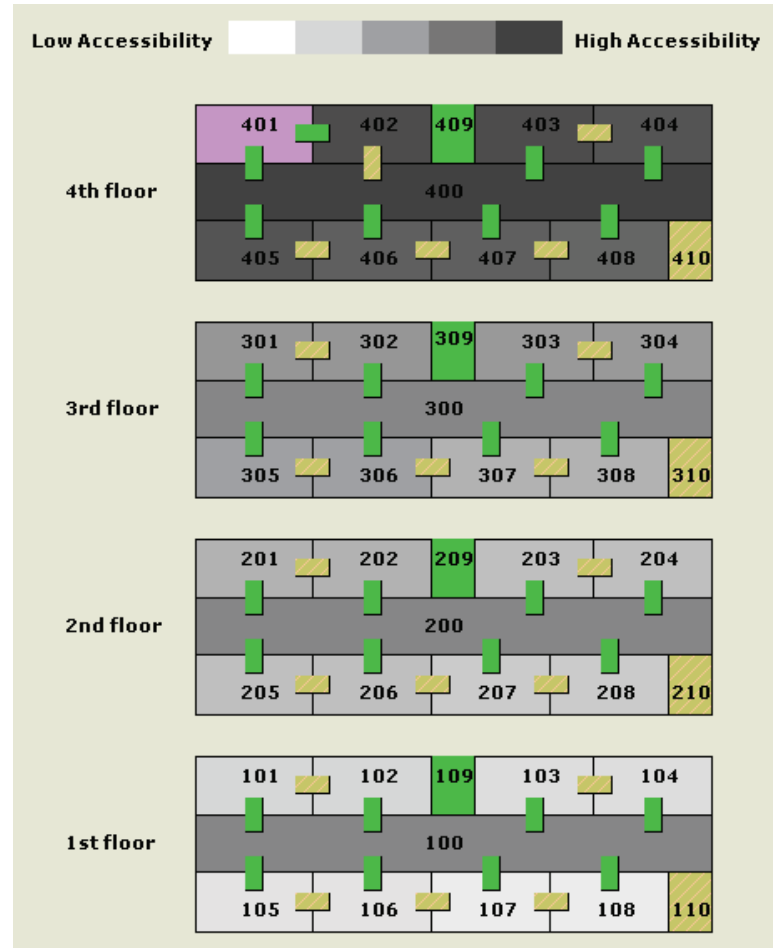

Figure 1b: Local Accessibility for Single Criterion for 401

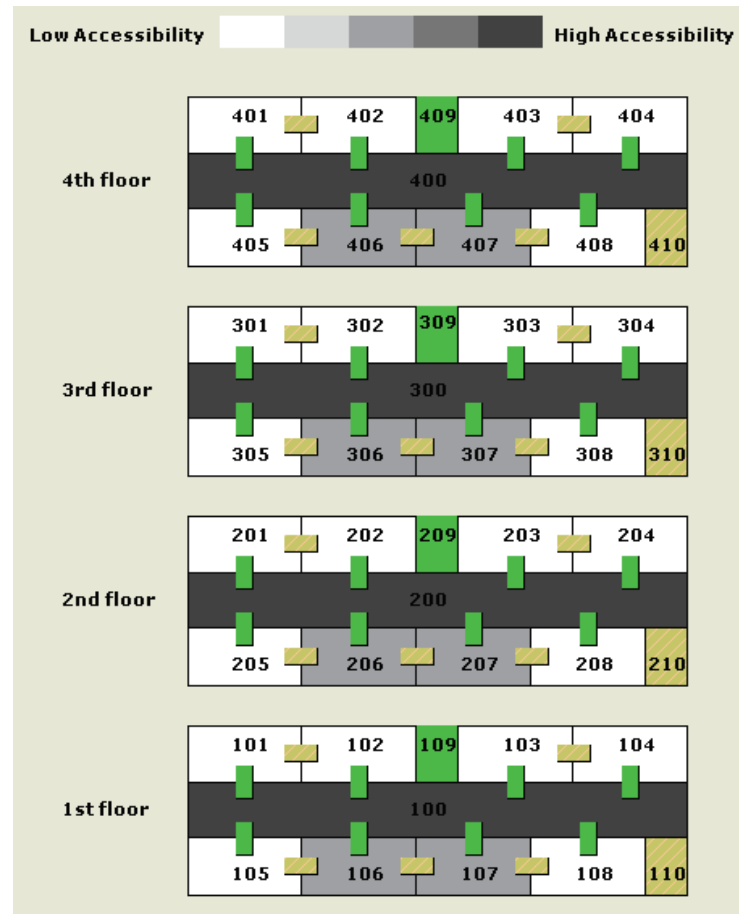

Figure 1c: Global Accessibility for Single Criterion 


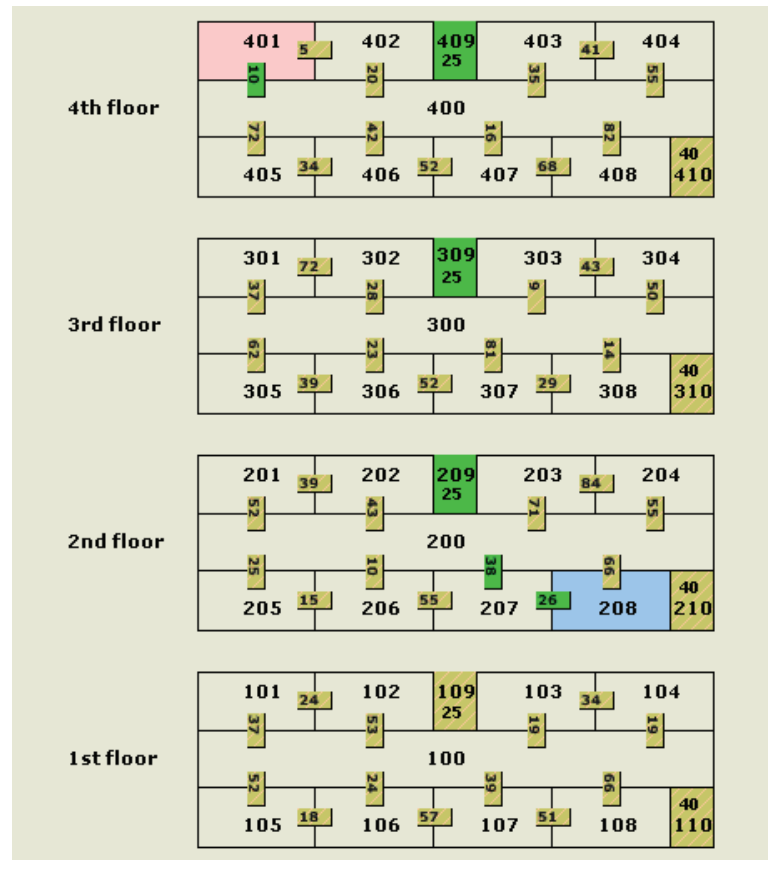

Figure 2a: Optimized Path for Different Cost Measures with Equal Weights from 401 to 208

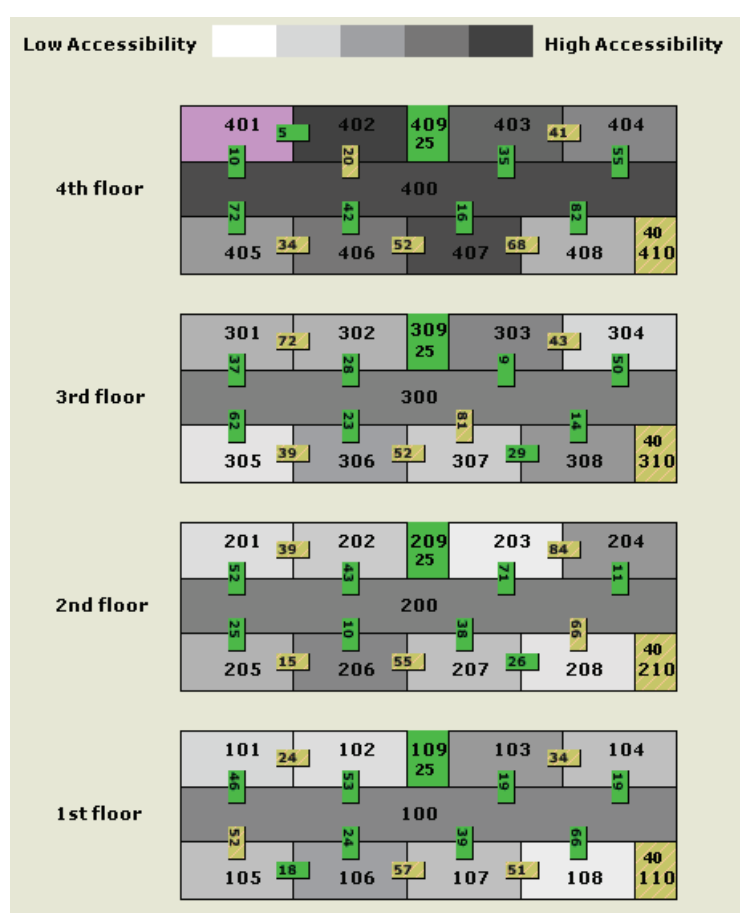

Figure 2b: Local Accessibility for Different Cost Measures with Equal Weights for 401

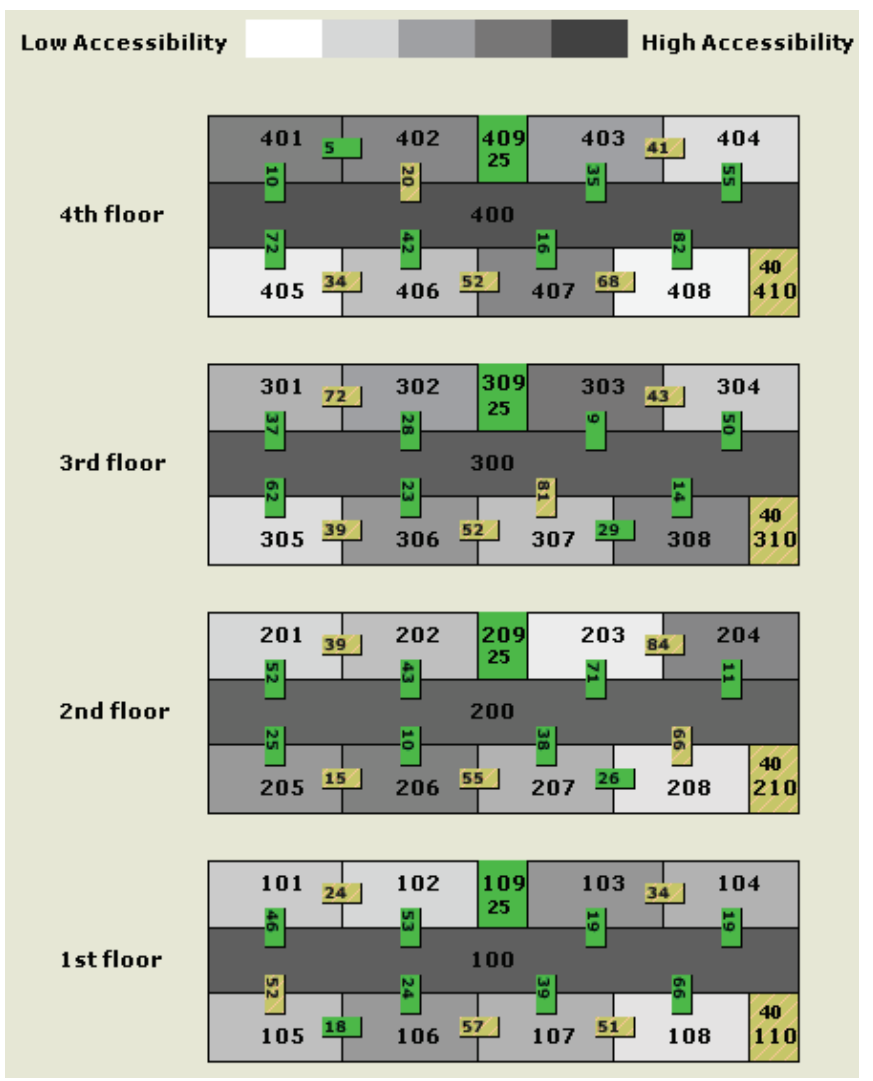

Figure 2c: Global Accessibility for Different Cost Measures with Equal Weights
For proof-of concept purposes, a multi-criteria template was manually created which defines the relative value for the travel overhead, levels of comfort and quality for each rooms used for setting criteria values for all the spaces in our building layout example

Consider going from room " 401 " to room "208" with equal weights given to the distance, comfort and quality cost measures. Results based on the multi-criteria analysis show the minimum-cost planning path to get from "401" to "208" in Figure 2a, the local accessibility of the space " 401 " is shown in Figure 2b, and the global accessibility of the building is shown in Figure 2c. 
Consider the path from spaces " 401 " to "208". Using unequal weight values for the distance, comfort and quality cost measures, the path to get from " 401 " to " 208 " is shown in Figure 3a, local accessibility of " 401 " is shown in Figure $3 \mathrm{~b}$, and global accessibility of the building is shown in Figure 3c.

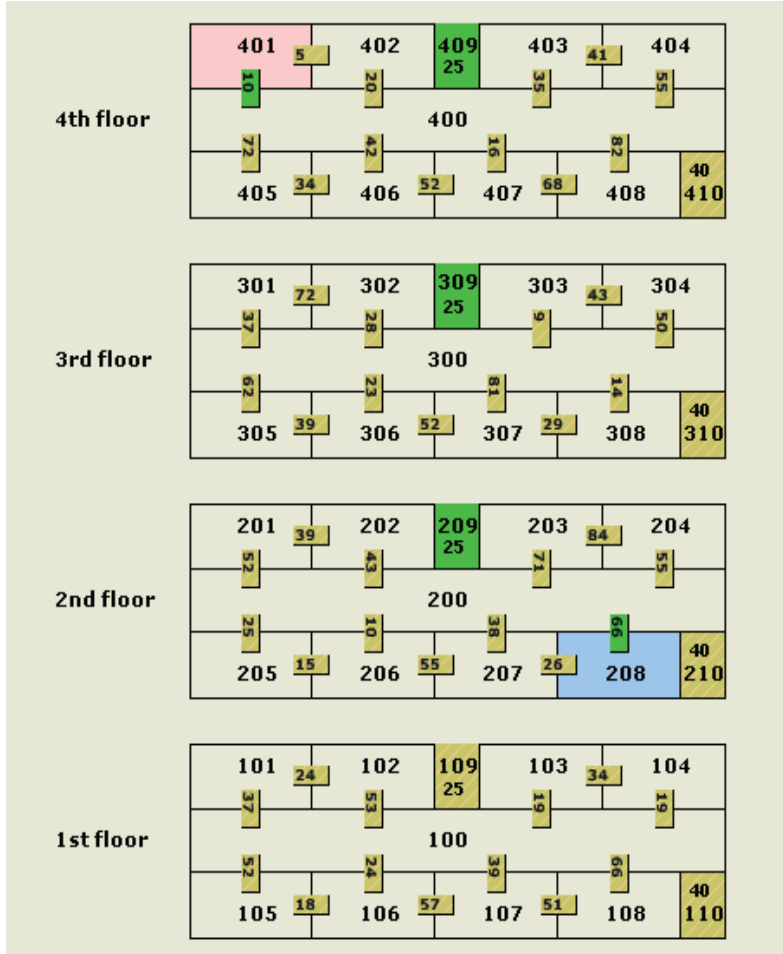

Figure 3a: Optimized Path for Cost Measures with Different Weights from 401 to 208

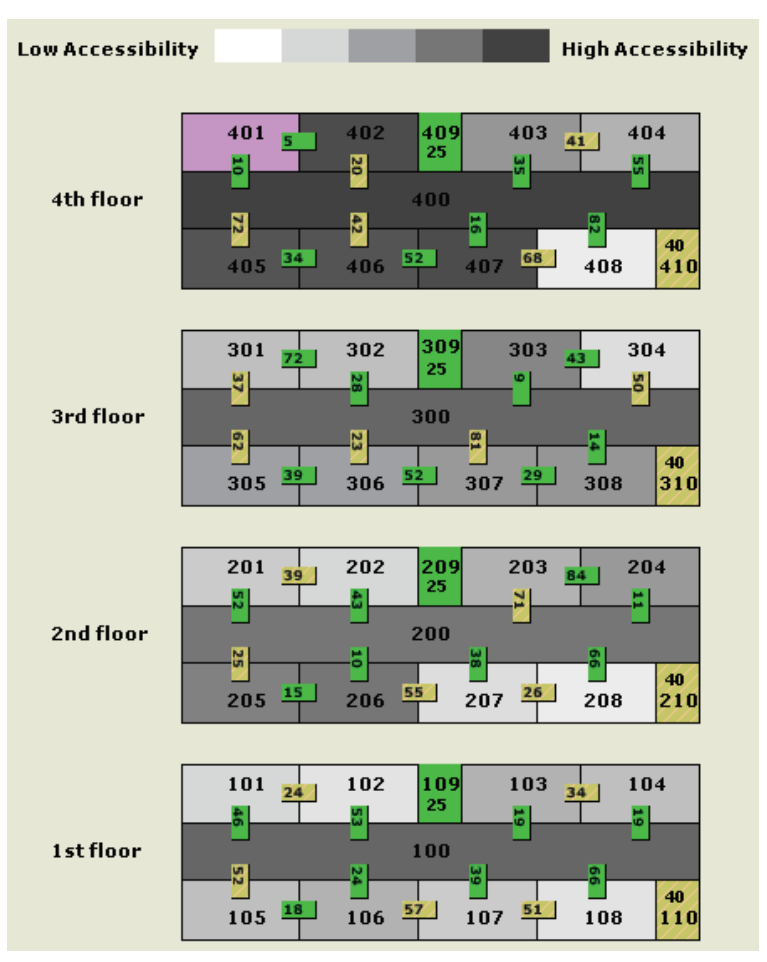

Figure 3b: Local Accessibility for Cost Measures with Different Weights for 401

It can be noticed that moving from single criterion to multi-criteria analysis can significantly alter the way by which accessibility can be defined and evaluated. Furthermore, the multi-criteria approach can be used to fine-tune the accessibility measure such as to emphasize a particular criterion over another depending on the design perspective.

Our argument extends the single criterion space syntax concept to multiple criteria analysis in order to better reflect the multi perspective nature of building layout and space use design.

This space analysis approach can be used as a mean of investigating the effect of spatial design on the local and global accessibility of a building layout. This act plays a role in the conceptual building design or client briefing stage by providing information on the degree of accessibility between a set of connected spaces in a spatial layout. Accessibility here is evaluated using two criteria: a standard accessibility from a single prospective based purely on the connections between the spaces, and a multi-criteria accessibility assessment, which combines various relevant cost measures. It also allows for the definition and evaluation of near and far relationships, and facilitates what-if accessibility and proximity scenarios. 


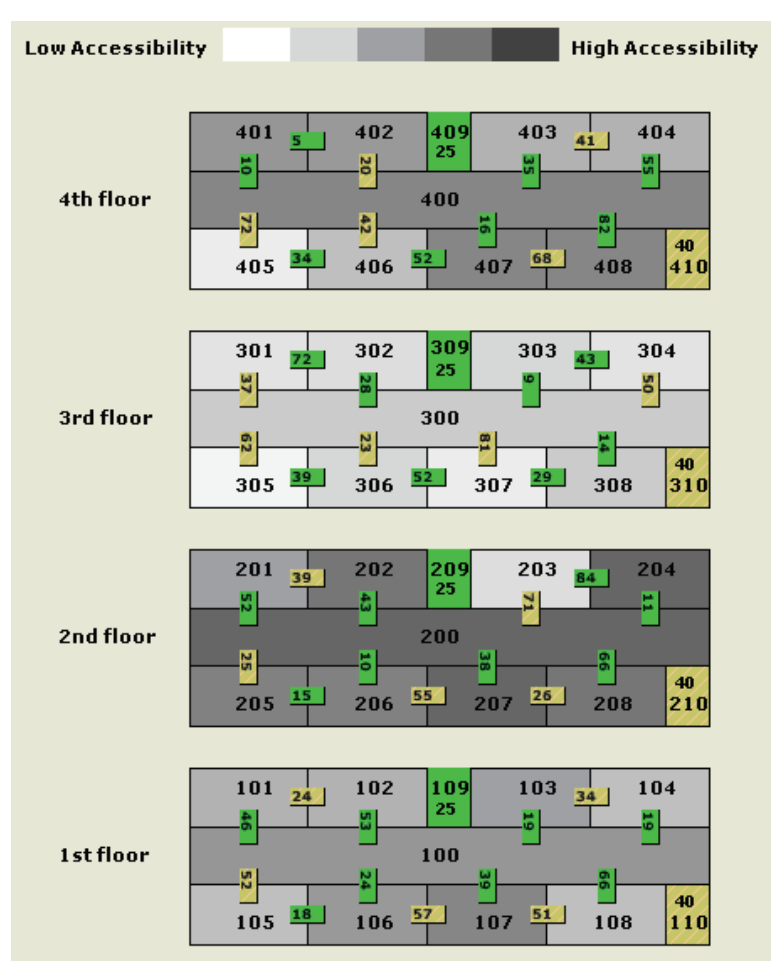

Figure 3c: Global Accessibility for Different Cost Measures with Different Weights

\section{Conclusion and Future Work}

The paper investigates the concept of adopting a multi-criteria accessibility analysis of spatial designs for building layouts. An initial proof of concept scenario been used to propose that the multi criteria approach would significantly influence the outcome of spatial layout analysis.

Future extensions to this work include the validation of the concept using a comprehensive real-world case study, and the use of stochastic algorithms for analysis and optimization of the allocation of spaces in buildings in order to achieve efficient use of the building layouts and generate enhanced spatial configurations.

\section{Acknowledgement}

The authors would like to thank A. Khan for his contribution to the prototyping stage of this research.

\section{References}

Dijkstra E.W. (1959). A note on two problems in connection with graphs. Numeriche Mathematik, 1, 269271.

Garling, T., Lindberg, E, \& Mantyla, T. (1983). Orientation in buildings: Effects familiarity, visual access, and orientation aids. Journal of Applied Psychology, 68, 117-186.

Gifford, R. (1997). Environmental psychology. Principles and practices (2nd ed.). USA.: Allyn and Bacon.

Goldberg, D. E. (1989). Genetic algorithms in search, optimization, and machine learning. AddisonWesley

Haq, S. (1999a). Expectation of exploration: Evaluating the effect of environmental variables on way finding. Proceedings of the 30 Environmental Design Research Association Conference- The Power or Imagination- EDRA30, Orlando, Fl. U.S.A., June 1999, 84-94.

Haq, S. (1999b). Can space syntax predict environmental cognition? Proceedings of the Space Syntax Second International Symposium, Brasilia, Brazil.

Hillier, B., Hanson, J., Peponis, J. Hudson, J. \& Burdet, R. (1983). Space syntax. A different urban perspective. Architec's Journal, 51-63.

Hillier, B. \& Hanson, J. (1984). The social logic of space. Cambridge: Cambridge University Press.

Hillier, B. (1996). Space is the machine. Cambridge University Press.

O'Neill, J. (1991). Evaluating a conceptual model of architectural legibility. Environment and Behavior, $23,259-284$. 
Ortega, A, Jiménez, E., Jiménez, C., Mercado, S., \& Estrada, C. (2001). Sintaxis espacial: Una herramienta para la evaluación de escenarios. Paper presented at the XV meeting of the Mexican Society of Behavioral Analysis, México.

Passini, R. (1984). Spatial representation: A way finding perspective. Journal of Environmental Psychology, 4, 154-164.

Passini, R. (1992). Way finding in architecture. New York: Van Nostrand Reinhold.

Peponis, J. \& Wineman, J. (2002). Spatial structure of environment and behavior. In R. Bechtel \& A. Churchman (Eds.). Handbook of environmental psychology (pp.271-291). New York: Wiley.

Peponis, J., Zimring, C., \& Choi, Y. (1990). Finding the building in way finding. Environment and Behavior, 22, 555-590.

Prestosky, J. \& Roskos-Ewoldsen, B. (2000). The relations among way finding strategy use, sense of direction, sex, familiarity and way finding ability. Journal of Environmental Psychology, 20, 177-191.

Riley, D. R. (1995). Patterns of construction space use in multi-story buildings. Journal of Construction Engineering and Management, ASCE, 121(4), 464-473.

Riley, D. R., \& Sanvido, V. E. (1997). Space planning method for multistory building construction. Journal of Construction Engineering and Management, ASCE 123(2), 171-180.

Rovine, M. \& Weisman, G. (1989). Sketch-map variables as predictors of way finding performance. Journal of Environmental Psychology, 9, 217-232.

Russell, S. \& Norvig P. (1995). Artificial intelligence: A modern approach. New Jersey: Prentice Hall.

Soltani, A. R., Tawfik H., \& Fernando T. (2002). A multi-criteria based path-finding application for construction site layouts. Proceedings of 6th Int'l Conference on Information Visualisation, July 2002. London, UK.

Thabet, W. \& Beliveau, Y. J. (1992). Modeling work space to schedule repetitive floors in multi-story buildings. Journal of Construction Engineering and Management, ASCE, 120 (1), 96-116.

Weisman, J. (1981). Evaluating architectural legibility. Way-finding in the built environment. Environment and Behavior, 13, 189-204.

\section{Biographies}

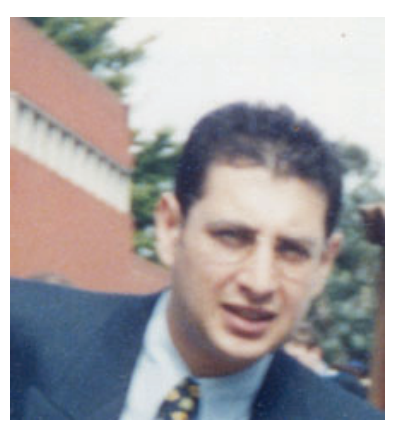

Hissam Tawfik is a Lecturer in Computing at Liverpool Hope University. He holds an MSc and PhD from in Computer Science and Engineering from University of Manchester (UMIST), UK. His research areas are in Artificial Intelligence and virtual reality applications. 


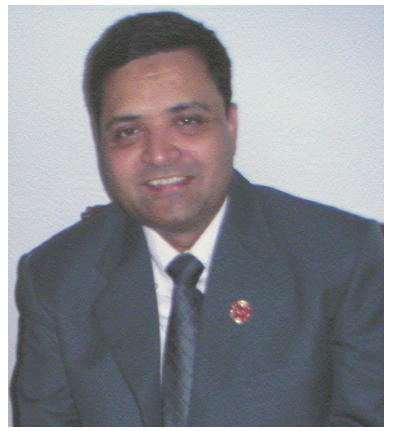

Atulya Nagar leads the Intelligent and Distributed Systems (IDS) Research Group at the Liverpool Hope University. He earned his $\mathrm{PhD}$ in Mathematics from the University of York and has worked for several years at Brunel University, UK. He has multidisciplinary research interests in: systems engineering, bioinformatics, and applied mathematics.

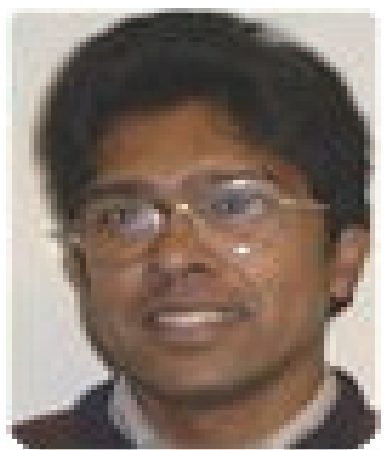

Terrence Fernando is a professor in Advanced Virtual Prototyping and is the director of the Future Workspaces Research Centre and the Technical Director of the ThinkLAB at the University of Salford, UK. 